УДК 316.3:304.9:30:101.2:008

DOI: $10.18101 / 1994-0866-2019-1-59-66$

\title{
ОСМЫСЛЕНИЕ ИСТОРИИ РАЗВИТИЯ ИДЕЙ С ПОЗИЦИИ АКТОРНО-СЕТЕВОЙ ТЕОРИИ
}

\author{
(C) Равочкин Никита Николаевич \\ кандидат философских наук, доцент, \\ Кемеровский государственный сельскохозяйственный институт \\ Россия, 650056, г. Кемерово, ул. Марковцева, 5 \\ E-mail: nickravochkin@mail.ru
}

\begin{abstract}
Автором статьи предпринимается попытка проведения социально-философского анализа развития идей, составляющих историю общественной интеллектуальной жизни, с позиции акторно-сетевой теории. В статье рассмотрено теоретическое поле понимания акторно-сетевой теории в контексте междисциплинарности. Анализируя переведенные первоисточники трудов Б. Латура и различные современные исследовательские работы, посвященные акторно-сетевой теории, автор определяет ее проблемное поле. Одной из наиболее важных задач, решенных автором, является раскрытие специфики субъект-объектных отношений в рамках рассматриваемой теории. Определено, что в ходе истории развития идей между акторами формируется «сеть». В заключении представлены выводы, отражающие значение акторносетевой теории в проведенном анализе, состоящее в выявлении автором двух взаимодополняющих аспектов интеллектуальной истории.
\end{abstract}

Ключевые слова: идеи; интеллектуальная история; сеть; акторы; Латур; общество; субъект; объект; динамика; интеллектуалы; реальность.

Для цитирования:

Равочкин Н. Н. Осмысление истории развития идей с позиции акторно-сетевой теории // Вестник Бурятского государственного университета. Философия. 2019. Вып. 1. C. 59-66.

Социальная философия обращается к анализу множества феноменов. Человек, являясь элементом социальной реальности или, по П. Бурдье, «актором», реализующим социальную практику как вид действия, становится одним из множества предметов и оснований для изучения как сущности реальности, так и истории ее становления [20]. Одним из феноменов социальной реальности является «история развития идей», или «интеллектуальная история». В рамках проводимых нами исследований данные понятия тождественны друг другу, поэтому для удобства читателей мы также будем использовать привычную категорию «интеллектуальная история».

Сегодня в мировой науке сложился и (со)существует ряд концепций и подходов к ее изучению. Одним из таковых способов ее осмысления является акторно-сетевая теория. Ее суть заключается в том, что всевозможные социальные объекты, будь то артефакты, животные, технические комплексы, используемые в социальной среде, рассматриваются как действующие единицы социальных отношений. В качестве одного из ее оснований считаем необходимым выделить следующее: в процессе жизнедеятельности люди через множественные взаимодействия создают и вступают в связи не только друг с другом, но в том числе и с вещами $[4 ; 10 ; 13 ; 21]$. Таким образом, общеизвестный факт об эволюции техники и технологий вполне логично полагать как одну из существенных причин воз- 
никновения и формирования данной теории $[13$, с. 6]. Так, анализ современных работ по проблемам, например, генезиса и стремительного развития интернета, не только подчеркивает актуализацию новых повесток для его исследования в различных аспектах междисциплинарности $[3 ; 10-12 ; 17-18]$, но также свидетельствует, что возникновение данного феномена «качественно изменило привычные традиционные практики, трансформировало социальное взаимодействие. Виртуальная реальность, обладающая специфической возможностью нивелировать пространственно-временные границы и субъект-объектные отношения, конституирует беспомощность классических концепций при описании современного социума» [16, с. 162]. В результате на уровне теоретических исследований при попытках дать описания обществу современности это свидетельствует о «беспомощности» классических концепций. В то же время на практическом уровне это приводит к потере привычных пространственных и временных связей между социальными субъектами, что в результате указывает на необходимость создания совершено нового определенного методологического аппарата $[5 ; 10]$.

Существенным проблемным полем, которое формируется в рамках акторносетевой теории, становится необходимость уточнения философского осмысления сущности соотношения «общество - природа». Проблема, на наш взгляд, заключается в том, что общепринятое разделение предметного поля гуманитарных, естественных, социальных и технических наук приводит к существенному разрыву в понимании соотношения данной пары. Так, если мы говорим о понимании общества через призму, например, социальных наук, то непременно обращает на себя внимание интерпретация общества не как части естественного мира, но как множества не имеющих существенных связей с предметами и отношениями объективного мира символических и смысловых элементов. В результате, как утверждает один из основоположников данной теории Б. Латур [14], замена элементов природы на множество знаков и символов социального мира «подразумевает способность заместить некоторый объект, относящийся к природе, другим, принадлежащим обществу, и показать, что именно он является истинной сущностью первого» [8, с. 344]. Из этого делаем вывод, что общество прекращает быть источником и основанием объяснения мироздания, поскольку признается искусственным образованием, и, как следствие, само должно быть объяснено. Как замечает А. С. Сивоконь, «отправной точкой в анализе социума акторносетевой теорией лежит постулат о главенствующей роли наук и технологии в процессе создания общества» [16, с. 163]. Это означает, что теперь не общество со всеми его структурами и возможностями формирует науку и научное сообщество, но именно последнее оказывает существенное формирующее влияние на все социальные структуры и элементы.

Именно интеллектуалы и ученые, занятые в (меж)дисциплинарных исследованиях и создающие посредством коммуникации меняющиеся во времени конкурентные сетевые среды взаимодействия, развития идей и теоретического обмена, оказывают обозначенное нами выше влияние на социальную структуру. Таким образом, в своих рассуждениях мы солидаризуемся с тезисом Н. С. Розова о том, что «социальная динамика (равно как и обобщающая ее историческая динамика) задается человеческим поведением» [15]. Новосибирский философ придает принципиальное значение поведению сплоченных групп, существенным из которых считает «поведение отдельных индивидов» [15]. Об «отдельности» как имманентном свойстве личностей интеллектуалов, полагаем, не стоит лишний 
раз упоминать, чтобы не выходить за рамки настоящего исследования, поэтому обратимся к рассмотрению влияния интеллектуалов на историю развития идей.

Такое влияние осуществляется в двух аспектах. Первый из них состоит в том, что, например, в лабораторных условиях [7] разрабатывается определенная информационная матрица, интеллектуальная конструкция, идея, которая в итоге оказывается крайне необходимой для общества в целом. Одним из подобных примеров, сочетающих теоретические и практические аспекты взаимодействия между интеллектуалами, могут являться медицинские исследования, направленные на лечение, в том числе смертельных заболеваний. Полученная специалистом определенного медицинского профиля информация делает его обладателем знания, с помощью которого он уже становится способным контролировать заболевание. Положение дел следующее: превалирующее большинство членов общества оказываются бессильными перед болезнью, а представители медицинской науки в результате лабораторных исследований становятся способными оказать необходимую помощь и победить болезнь [7]. В результате такой исследователь или даже целый коллектив, кто первый(-ми) открывает тот или иной способ лечения конкретного заболевания, получает(-ют) определенный символ, который М. Фуко характеризует знаменитой максимой «власть - знание» [22]. Будучи занятыми в области умственного труда, научные исследователи оформляют идеи, способные на уровне интеллектуальных властных полномочий осуществить соответствующее влияние на дальнейшее развитие как конкретного социального класса, так и целого общества [1]. В итоге обладание символической конструкцией в дальнейшем оказывает определенное влияние на общественное развитие.

Другой аспект влияния лабораторий и научных организаций на общество прослеживается: 1) в исходном получении и обладании исследователем и/или коллективом некоторым знанием; 2) последующем выяснении и отборе способов его применения на практике [7]. Эти интеллектуалы вне зависимости, порознь или совместно, стремятся изменить и в конце концов изменяют потребности общества, задавая тем самым императив прохождения через лабораторию для их реализации, главным образом, витальных [7]. При этом для эффективного использования знаний на практике крайне необходимым оказывается распространение всех условий, которые существуют в исследовательской лаборатории. Это объяснимо, поскольку «лабораторные практики внедряются в повседневную жизнь, тем самым, безусловно, изменяя общественное устройство. Общество корректируется и реформируется через содержание науки, которая трансформирует социальные практики» [16, с. 164] с целью обеспечения воспроизводства мира таким, каким его делает наука. Из этой посылки сторонники акторносетевой теории строят умозаключение, что на микроуровне лаборатория как микросоциальный субъект формирует социум, который является субъектом макросоциальным.

Здесь нам следует сделать вывод о том, что любая идея, которая формируется в ходе научного поиска в стенах лаборатории, в определенном смысле становится основанием и толчком для развития и совершенствования социальной ткани. Вместе с тем любая идея, формируемая в условиях лаборатории, представляет собой элемент и результат интеллектуальной деятельности исследователя [7]. Таким образом, развитие истории идей требует от научного субъекта ведения активной деятельности, которая в конечном счете трансформируется, вплетаясь в 
развитие интеллектуальной деятельности общепланетарного масштаба. В качестве факторов, предполагающих и способствующих развитию интеллектуальной деятельности, мы выделяем «внутренние и внешние вызовы» в значении, которое придает им А. Тойнби [23].

Не менее важным моментом в понимании развития истории идей в рамках акторно-сетевой теории становится трактовка ее представителями происхождения и развития феноменов культуры и социальной ткани. Социальные, политические, экономические и прочие субъекты уже рассматриваются не только и не столько как прикрепленные к определенным условиям. Кроме этого, социальными субъектами становятся не только люди и большие и малые социальные группы, но также и созданные людьми феномены культуры в самом широком значении данного термина. Данная теория осуществляет критическую риторику по поводу отношений к взаимодействию «человек - предмет», если последние воспринимаются «вторично» культурно-социальному процессу, что указывает на симметричность и взаимообусловливаемость материального и символического порядков. М. А. Ерофеева отмечает, что в моделях данной теории «уравнивается статус людей и вещей в грамматическом отношении» [5]. Стоит указать, что такие характеристики отношений между человеческими и не-нечеловеческими акторами приводят к порождению гибридной сети взаимоотношений материального и символического («онтология гибридного мира») [10]. Именно в этом мы усматриваем преимущества акторно-сетевой теории перед подходами социальных конструктивистов и научных реалистов. Таким образом, различные социальные артефакты также являются действующими единицами социальных отношений. Это означает, что влияние результатов интеллектуальной деятельности исследователей распространяется не только на саму социальную ткань как систему отношений между социальными субъектами, но также и на существующие и используемые в существующей системе социальных отношений артефакты. Более того, можно предположить, что такие артефакты могут со своей стороны оказывать более или менее существенное влияние на развитие идей и интеллектуальную историю социума.

Данное утверждение реализуется в достаточно интересной интерпретации субъект-объектных отношений. Речь идет о том, что в классическом понимании субъект понимался как носитель сознания, то есть тот, кто осознает проводимые действия и способен нести ответственность за совершенное действие. Кроме того, классическое понимание сознание утверждает приоритет субъекта над объектом, в результате чего формируется доминирующая позиция субъекта над объектом. В очередной раз ссылаясь на А. С. Сивоконь, отмечаем, что «акторно-сетевая концепция «освобождает» объект, выводя его на один уровень с субъектом в контексте потенциального и актуального действия. Действие как таковое не может быть дифференцировано по уровням и важности, поэтому не имеет значения, кто или что его совершает» [6, с. 164].

Согласно Латуру, объект прекращает быть «покорным»в значении «подручного средства», перестает быть исключительно инструментальным как способным выполнять только свой четко определенный практический функционал. В рамках акторно-сетевой теории объект рассматривается как то, что способно «отвечать», то есть выходить за пределы собственного функционализма и существовать как самостоятельный, независимый предмет. Объекты, которые в традиционном смысле этого слова представляли собой вещи, артефакты, в общем - 
все то, на что была направлена активность субъекта, теперь обретают способность «говорить» сами за себя, следовательно, как и субъекты создавать и вступать в социальные связи, а также действовать и опосредовать действия «других». Из этого следует, что любой социальный артефакт, не являющийся субъектом в своем «классическом» значении, в определенном смысле становится элементом системы отношений и деятельности, причем занимает достаточно активную позицию в актуализации принципа деятельности. При этом полностью нивелируется дихотомия «субъект-объект», а основной акцент делается на системе отношений, выраженной в деятельности всех акторов (вне зависимости субъектов или объектов) деятельности как таковой. При этом сами акторы становятся производными от некоторых устойчивых множеств или отношений [4, с. 22].

Представленная логика означает для нас следующее. Существующие в социальной ткани артефакты, будь то созданные механизмы или даже животные, являются активными участниками социальных отношений благодаря социально приемлемым и соответствующим образом воспринимаемым и понимаемым формам деятельности. Именно по этой причине любой социальный актор вынуждает социальную систему находиться в подвижном состоянии. В конечном счете это указывает, что исследователь, являясь активным членом общества, оказывает существенное влияние на социальную ткань. При этом, как было отмечено выше, развитие идей как интеллектуальных конструкций, предлагаемых ученым, позволяет обществу развиваться, приводя в итоге к развитию интеллектуальной истории общества как такового. Обратимся и к другой стороне значения. Поскольку любой объект, понимаемый в рамках акторно-сетевой теории как социальный актор, обладает свойством активной деятельности, значит справедливо отметить принципиальное влияние каждого актора на исследователя, причем некоторые из них могут повлиять коренным образом. В итоге объект может быть понят нами как результат деятельности того или иного исследователя, чьи научные изыскания привели к формированию конкретного социального феномена, используемого в конкретной области [19]. Активная деятельность такого актора, как продукт деятельности исследователя, по существу, приводит к тому, что каждый такой актор оказывает существенное влияние на деятельность исследователей. Это в значительной степени влияет на формирование принципиально новых идей, которые впоследствии реализуются на практике в ходе изобретения и формирования все новых и новых последующих акторов как объектов, но уже в классическом значении данного термина.

В результате мы видим существование множественных взаимных зависимостей влияния исследователей, работающих в лабораториях и формирующих принципиально новые идеи для развития социальных связей и отношений, и созданных ими продуктов как акторов, имеющих свойство активной «деятельности» в области социальных связей и отношений. Такое взаимное влияние приводит к развитию интеллектуальной сферы в конкретной социальной среде. Таким образом, в ходе своего развития общество через деятельность отдельных индивидов реализует развитие интеллектуальной истории. В ходе истории развития идей формируется так называемая «циркуляция», суть которой заключается в перемещении полученных знаний. Вместе со знаниями перемещаются и связанные со словами и записями сущности. Согласно логике теории, записи тоже становятся полноправными участниками социального процесса и процесса развития интеллектуальной истории: «циркуляция позволяет нам убедиться в стирании 
границы между словом и вещью, поскольку объект и высказывание о нем становятся неразделимы, они взаимопроникают друг в друга» [16, с. 165]. Процесс циркуляции записей приводит к порождению «сети». На наш взгляд, наиболее полную интерпретацию латуровской «сети» дает В. С. Вахштайн как «глобализованного, распределенного в пространстве и времени человеческого взаимодействия, поделенного на дискретные «мобильности» и опосредованного объектами» [2]. Из этого допускается вывод, что общество, будучи сетью, подобной виртуальной сети Интернет, существует исключительно в действии. Его также возможно рассматривать как социальный фотон, способный существовать в вакууме только двигаясь со скоростью света.

Здесь мы обнаруживаем определенное противоречие понимания развития интеллектуальной истории представителями акторно-сетевой теории. С одной стороны, Б Латур, М. Каллон и другие представители данного направления полагают необходимость постоянного взаимодействия не только для существования общества, но для и развития социальной ткани, на основании которого происходит исторический процесс развития идей. С другой — их идейные основания испытали существенное влияние постмодернистов, главным образом Ж. Бодрийяра и М. Фуко. Приведем одну из идей, а именно являющуюся фундаментальной для постмодернизма идею ризомы, которая понимается как показатель внеструктурности, как нечто, не имеющее четкой организации и заранее заданной структуры. Ризома предполагает множественность видов и способов организации пространства и времени, социальной ткани и социальных взаимодействий [6]. В результате перед нами встает вопрос: возможно ли хоть скольконибудь организованное понимание времени? Исходя из проведенного анализа, формирование, эпистемология и понимание интеллектуальной истории становятся как минимум затруднительными, как максимум - попросту невозможными.

Подведем итоги работы. Интеллектуальная история в рамках акторносетевой теории понимается как процесс, который детерминирован двумя взаимодополняющими аспектами. С одной стороны, исследователи, создающие принципиально новые теоретические и практические положения, оказывают существенное идейное влияние на развитие социума и, как следствие, реализуется интеллектуальная история. Другой аспект заключается в понимании сущности используемых в обществе предметов. Уже не как объектов, испытывающих на себе постоянное воздействие со стороны субъектов, но как акторов, равноправно и равноценно участвующих в формировании как социальной ткани, так и интеллектуальной истории, оказывая существенное влияние на исследователей, которые вынуждены реагировать на появление новых идей. Вместе с тем мы отмечаем некоторые существующие затруднения, связанные с пониманием интеллектуальной истории в рамках рассматриваемой теории. Речь идет о методологической близости постмодернистского понимания истории, в котором исторический процесс сведен к ризомному описанию истории как процесса, не имеющего структурного характера.

Лumepamypa

1. Балаян А. А., Томин Л. В. Акторно-сетевая теория в контексте дискуссий об идеологии и политической онтологии // Вестник Балтийского федерального университета им. И. Канта. Сер. Гуманитарные и общественные науки. 2018. № 1. С. 88-94.

2. Вахштайн В. С. Возвращение материального. «Пространства», «сети», «потоки» в акторно-сетевой теории // Социологическое обозрение. 2005. Т. 4, № 1. С. 94-115. 
3. Горбачева А. Г. Конструктивные и деструктивные коммуникативные практики людей в сети Интернет // Идеи и идеалы. 2013. Т. 2, № 3. С. 17-25.

4. Ерофеева М. А. Акторно-сетевая теория и проблема социального действия // Coциология власти. 2015. Т. 27, № 1. С. 17-36.

5. Ерофеева М. А. Социология И. Гофмана в контексте развития теории социального действия: дис. ... канд. соц. наук. СПб.: Изд-во С.-Петерб. гос. ун-та, 2015. 165 с.

6. Козлова О. Д., Киндеркнехт А. С. Феномен клипового мышления: между стереотипом и ризомой // Вопросы философии. 2018. № 2. С. 39-45.

7. Латур Б. Дайте мне лабораторию и я переверну мир [Электронный ресурс] // Логос. 2002. № 5-6(35). URL: http://www.ruthenia.ru/logos/number/35/10.pdf (дата обращения: 19.09.2018).

8. Латур Б. Когда вещи дают отпор: возможный вклад «исследований науки» в общественные науки // Социология вещей. М.: Территория будущего, 2006. С. 342-365.

9. Лупанов В. Н. Интернет как объект социологического исследования (к вопросу о развитии социологической сети в Интернете, web-сети) // Информационное общество. 2001. № 1. C. 40-43.

10. Малов Е. А. Феномен социальных сетей: акторно-сетевой контекст, теоретикометодологический анализ: дис. ... канд. соц. наук. СПб.: Изд-во С.-Петерб. гос. ун-та, 2015. $236 \mathrm{c}$.

11. Мальченков И. Е. Феноменологическая реконструкция реальности повседневной жизни в сети Интернет // Медиафилософия. 2011. Т. 7, № 7. С. 142-153.

12. Петрова Е. И. Интернет-СМИ и социальные сети: этапы конвергенции // Коммуникативные исследования. 2014. № 2(2). С. 128-133.

13. Писарев А., Астахов С., Гавриленко С. Акторно-сетевая теория: незавершенная сборка // Философско-литературный журнал Логос. 2017. Т. 27, № 1(116). С. 1-40.

14. Полонская И. Н. Альтернативная социология Б. Латура: к характеристике методологии // Теория и практика общественного развития. 2012. № 6. С. 72-75.

15. Розов Н. С. Ритуалы, институты и ресурсы: социальные основы трансформации менталитета // Ценности и смыслы. 2010. № 5(8). С. 50-67.

16. Сивоконь А. С. Акторно-сетевой подход: истоки и перспективы в социальнофилософском дискурсе // Ученые записки Казанского университета. Сер. Гуманитарные науки. 2015. Т. 157, № 1. С. 162-169.

17. Черняева К. О. Культурная идентификация в социальных сетях Интернета // Вестник Поволжской академии государственной службы. 2010. № 1 (22). С. 209-214.

18. Черняков А. Н., Дунаев Р. А. Политический дискурс в аспекте самореализации в сети Интернет // Наука. Искусство. Культура. 2016. № 1(9). С. 107-111.

19. Шаев Ю. М. Интернет вещей и акторно-сетевая теория Б. Латура: методология и онтология // Гуманитарный вектор. 2017. Т. 12, № 3. С. 40-45.

20. Bourdieu P. The Logic of Practice. Polity Press, 1990. 340 p.

21. Czarniawska B. Bruno Latour and Niklas Luhmann as organization theorists // European Management Journal. 2017. Vol. 35. Issue 2. P. 145-150. URL: https://doi.org/10.1016/j.emj.2017.02.005 (дата обращения: 02.03.2017).

22. Foucault M. Lectures on the Will to Know: Lectures at the Collège de France 19701971 and Oedipal Knowledge. Basingtoke: Picador, 2014. 320 p.

23. Тойнби А. Дж. Постижение истории. М.: Айрис-пресс. 2010. 640 с. 


\section{HISTORICAL REFLECTION OF IDEAS DEVELOPMENT}

\section{FROM THE PERSPECTIVE OF ACTOR-NETWORK THEORY}

\section{Nikita N. Ravochkin}

Cand. Sci. (Philos.), A/Prof.,

Kemerovo State Agricultural Institute,

5 Markovtseva St., Kemerovo 650056, Russia

E-mail: nickravochkin@mail.ru

In the article we have made an attempt to carry out a socio-philosophical analysis of the development of ideas that make up the history of social intellectual life from the perspective of actor-network theory. The theoretical field of understanding of actor-network theory in the context of interdisciplinarity is considered. Analyzing the translations of B. Latour's original works and a number of modern researches devoted to actor-network theory, we have identified its problematic field. The specificity of subject-object relations is disclosed within the framework of the considered theory. It has been determined that throughout the history of ideas development a "network" between the actors is formed. The research of ideas development carried out from the perspective of actornetwork theory allowed us to reveal two complementary aspects of intellectual history. Keywords: ideas; intellectual history; network; actors; Latour; society; subject; object; dynamics; intellectuals; reality. 